\title{
Overactive Bladder Prescribing Considerations: The Role of Polypharmacy, Anticholinergic Burden, and CYP2D6 Drug-Drug Interactions
}

\author{
Matthew P. Rutman ${ }^{1}$ (D) John R. Horn ${ }^{2} \cdot$ Diane K. Newman $^{3} \cdot$ Richard G. Stefanacci $^{4}$
}

Accepted: 26 February 2021 / Published online: 12 March 2021

(c) The Author(s) 2021

\begin{abstract}
Overactive bladder $(\mathrm{OAB})$ is a common disorder in the general population, and the prevalence increases with age. Adults with OAB typically have a greater number of comorbid conditions, such as hypertension, depression, and dementia, compared with adults without OAB. Subsequent to an increased number of comorbidities, adults with OAB take a greater number of concomitant medications, which may increase the risk of potentially harmful drug-drug interactions. There are two important considerations for many of the medications approved for the treatment of OAB in the USA: anticholinergic burden and potential for drug-drug interactions, notably related to cytochrome P450 (CYP) 2D6, which is responsible for the metabolism of approximately $25 \%$ of all drugs. A substantial number of drugs used for the treatment of OAB and comorbid conditions (e.g., cardiovascular and neurologic disorders) are CYP2D6 substrates or inhibitors. Furthermore, a substantial number of drugs with CYP2D6 properties also have strong anticholinergic properties. Here, we review polypharmacy associated with $\mathrm{OAB}$ and its common comorbidities, identify drugs with reported anticholinergic properties, and provide an overview of clinically relevant drug-drug interactions in the treatment of OAB as they relate to CYP2D6 metabolism. This review aims to provide clinicians with essential information necessary for making treatment decisions when managing OAB.
\end{abstract}

\section{Introduction}

An estimated $23 \%$ of Americans $\geq 40$ years old have bothersome symptoms of overactive bladder (OAB) [1], and the proportion of adults who report urgency or urgency urinary incontinence increases with age in both men and women $[1,2]$. Among residents of long-term care (LTC) facilities who are $\geq 65$ years old, approximately $65-70 \%$ report urinary incontinence $[3,4]$, which is the second-leading cause for the placement of older adults into care facilities [5]. Compared to individuals without $\mathrm{OAB}$, adults with $\mathrm{OAB}$ have a significantly higher prevalence of comorbid medical

Matthew P. Rutman

mr2423@cumc.columbia.edu

1 Columbia University, 11th Floor, HIP, 161 Ft. Washington Avenue, New York, NY 10032, USA

2 School of Pharmacy, Department of Pharmacy, University of Washington, Seattle, WA, USA

3 Perelman School of Medicine, University of Pennsylvania, Philadelphia, PA, USA

4 Jefferson College of Population Health, Thomas Jefferson University, Philadelphia, PA, USA

\section{Key Points}

Adults with overactive bladder $(\mathrm{OAB})$ have high rates of comorbid medical conditions (e.g., cardiovascular, neurologic, psychiatric) and polypharmacy; many drugs used for the treatment of $\mathrm{OAB}$ or for common comorbidities have anticholinergic properties, are substrates of cytochrome P450 (CYP) 2D6, or are both.

When co-administered with treatments for $\mathrm{OAB}$ that are CYP2D6 inhibitors, CYP2D6 substrates with anticholinergic properties may lead to effects such as impaired cognition, while exposure to substrates of CYP2D6 may lead to potentially harmful drug-drug interactions and adverse effects.

Many drugs with clinically significant CYP2D6 metabolism have anticholinergic properties (and thus are associated with an increased risk of dementia and falls) and/or are associated with a variety of safety concerns including the risk of QT prolongation and other boxed warnings or contraindications when co-administered with CYP2D6 inhibitors. 
conditions, particularly cardiovascular and central nervous system (CNS) comorbidities [6,7]. This holds true for older adults, as those $\geq 65$ years old with $\mathrm{OAB}$ continue to experience a greater number of comorbid medical conditions than age-matched cohorts without $\mathrm{OAB}$; among adults with $\mathrm{OAB}$, those $\geq 75$ years old have a greater number of comorbidities than those 65-74 years old [8].

The 2019 American Urological Association/Society of Urodynamics, Female Pelvic Medicine and Urogenital Reconstruction guidelines for the treatment of OAB (Table 1) recommend behavioral therapy as first-line treatment, which may be combined with pharmacotherapy; second-line treatment includes oral anticholinergics or $\beta_{3}$-adrenergic agonists [9]. Treatment with anticholinergics, however, is associated with well-known side effects such as dry mouth, blurred vision, and constipation [10] and, perhaps more importantly, is associated with an increased risk of falls [11] and incident dementia [12-14]. Therefore, patients should be monitored for adverse drug reactions while taking anticholinergic treatments, and doses or treatments should be modified as necessary [9]. Furthermore, the American Geriatrics Society Beers Criteria ${ }^{\circledR}$ for Potentially Inappropriate Medication Use in Older Adults provides guidance regarding safety and dosing considerations in older adults for not only anticholinergics (e.g., strongly anticholinergic drugs such as chlorpheniramine, diphenhydramine, and amitriptyline are considered inappropriate), but also for other drug classes (e.g., antidepressants, skeletal muscle relaxants, and peripheral $\alpha_{1}$-blockers are considered inappropriate) [15].

Given the greater number of comorbid conditions experienced by adults with $\mathrm{OAB}$ and the subsequently greater number of pharmacologic treatments prescribed [6-8], there is an increased risk of potentially clinically relevant drugdrug interactions (DDIs) in this population. Furthermore, a substantial number of drugs used to treat $\mathrm{OAB}$ and comorbid conditions, such as cardiovascular, neurologic, and psychiatric disorders, are CYP2D6 substrates or inhibitors. Drugs that inhibit CYP2D6 lead to increased plasma concentrations of drugs that are substrates of the enzyme, increasing the possibility of experiencing adverse events and toxicity. While not a focus of this review, other liver-based metabolic pathways, including CYP3A4 and CYP2B6, should also be considered [16].

Computerized physician order entry (CPOE) and prescribing systems are widely used with the goal of simplifying the prescribing process and identifying potential DDIs to minimize the risk of adverse effects. However, some CPOE systems remain problematic and may increase the risk of certain types of unforeseen prescribing errors, revealing new opportunities for error reduction [17]. Electronic health record (EHR) databases, which allow clinicians to track the potential benefits and risks of medical treatments, have been implemented by a substantial percentage of physician offices, and by 2014 , approximately $74 \%$ of officebased physicians had implemented certified EHRs [18]. Electronic health records can provide decision-making support and can also alert clinicians of potential DDIs, similar to CPOE systems. However, while certified EHRs do exist, such databases are not regulated or standardized, and safety performance varies among the different EHR vendors [19]. As such, it is necessary for healthcare providers who treat patients with $\mathrm{OAB}$ to be aware of relevant DDIs so as not to rely solely on CPOE systems or EHRs to determine contraindications and the potential for clinically meaningful DDIs.

The aim of this review is to evaluate polypharmacy associated with $\mathrm{OAB}$ comorbidities and the implications relating to anticholinergic burden. The potential for clinically relevant CYP2D6-related DDIs is also explored to provide essential information for clinicians treating patients with $\mathrm{OAB}$.

Table 1 American Urological Association/Society of Urodynamics, Female Pelvic Medicine and Urogenital Reconstruction guidelines for the treatment of overactive bladder (adapted from [9])

\begin{tabular}{|c|c|c|}
\hline Strategy & Treatment & Notes \\
\hline First line & $\begin{array}{l}\text { Behavioral therapy consisting of bladder training, bladder control } \\
\text { strategies, pelvic floor muscle training, and fluid management }\end{array}$ & May be combined with pharmacologic treatment \\
\hline Second line & $\begin{array}{l}\text { Pharmacologic management consisting of oral anticholinergics } \\
\text { (darifenacin, fesoterodine, oxybutynin, solifenacin, tolterodine, } \\
\text { trospium) and/or } \beta_{3} \text {-adrenergic receptor agonists (mirabegron, } \\
\text { vibegron) }\end{array}$ & $\begin{array}{l}\text { Extended-release formulations are preferable; transdermal } \\
\text { formulations may be offered; consider dose modification } \\
\text { or alternate medication if patients do not respond to initial } \\
\text { treatment }\end{array}$ \\
\hline Third line & $\begin{array}{l}\text { Intradetrusor onabotulinumtoxinA or nerve stimulation (periph- } \\
\text { eral nerve stimulation or sacral neuromodulation) }\end{array}$ & $\begin{array}{l}\text { Patient populations should be carefully selected, and patients } \\
\text { must be thoroughly counseled }\end{array}$ \\
\hline Fourth line & Augmentation cystoplasty or urinary diversion & Consider for severe, refractory, or complicated patients \\
\hline
\end{tabular}




\section{Comorbidities and Polypharmacy in Patients with OAB}

Overall, adults with $\mathrm{OAB}$ experience a greater number of comorbidities compared with those without $\mathrm{OAB}[6,20$, 21]. Prevalence of comorbidities in older adults is substantial, with one database analysis reporting that adults $65-74$ years old may experience an average of 16 comorbid medical conditions in a 12-month period, whereas adults $\geq 75$ years old may experience an average of 20 [8]. Cardiovascular and neuropsychiatric comorbidities among adults with $\mathrm{OAB}$ are of particular interest given that the mainstays of pharmacologic treatment of $\mathrm{OAB}$ are anticholinergic medications, including oxybutynin, tolterodine, fesoterodine, and solifenacin, among others, that have well-known cardiovascular and neurologic side effects [22, 23]. Indeed, adults with $\mathrm{OAB}$ have a greater number of pre-existing neuropsychiatric disorders, including psychosis, nonpsychotic mental disorders, and dementia, compared with individuals without OAB; they also have a greater number of cardiovascular comorbidities such as hypertension and cardiac conduction disorders [6, 7].

Subsequent to a greater number of comorbid conditions, older adults with $\mathrm{OAB}$ are more likely to be taking a greater number of concomitant medications, particularly those used to treat cardiovascular and psychiatric conditions, than older adults without $\mathrm{OAB}$ [8]. Furthermore, adults with $\mathrm{OAB}$ have significantly increased use of anticholinergic medications than individuals without $\mathrm{OAB}$ [6], which has the potential to increase adverse effects or toxicity. A pooled analysis of ten clinical trials of fesoterodine for the treatment of OAB in participants $\geq 65$ years old showed that the probability of experiencing a treatment-emergent adverse event significantly increased with increasing baseline concomitant diseases and medications [24].

In LTC facilities, the prevalence of OAB and/or urinary incontinence is high, with reports of $65-70 \%$ [3, 4]. Approximately $89 \%$ of nursing home residents need assistance with toileting, and $92 \%$ need assistance with walking or locomotion [25]. Consistent with the general population, residents of LTC facilities with urinary incontinence and/or OAB have a significantly higher prevalence of comorbidities such as hypertension, hyperlipidemia, dementia, depression, and anxiety disorders than residents without OAB [4]. Additionally, rates of frailty in LTC facilities are high, with one report suggesting that approximately $85 \%$ of LTC residents are frail [26], which may be related to comorbidities. Polypharmacy, a term with a broad range of definitions in the literature but commonly defined as taking five or more medications [27], in residents of LTC facilities is also high overall, with a recent systematic reviewing suggesting that $91 \%$ and $65 \%$ of LTC residents are taking more than five or more than ten medications, respectively [28]. Residents in LTC facilities with $\mathrm{OAB}$ have high rates of use of anticholinergic medications [29] and have significantly greater concomitant medication use, including use of diuretics, anxiolytics, and antipsychotics, compared with their age-matched cohorts [4]. In addition to highlighting challenges with polypharmacy, these obstacles to pharmacologic treatment highlight a need for behavioral treatments, which can be beneficial in this population.

\section{Healthcare Burden of Polypharmacy}

Management of $\mathrm{OAB}$ in older adults can be challenging given the high prevalence of polypharmacy [4, 8, 28, 29], which can lead to safety concerns and an increased risk of DDIs, potentially increasing healthcare resource utilization and costs. Indeed, current methods for treating patients with $\mathrm{OAB}$ has been shown to increase the healthcare burden and costs, typically because of the high prevalence of comorbid conditions [20, 21, 30]. Drug-drug interactions experienced by patients receiving polypharmacy can compound the economic burden because DDIs are associated with increased costs of hospitalization [31]. Additionally, the increased need for assistance with toileting and walking/locomotion [25] can place an extra burden on LTC staff that could be further encumbered when coupled with managing DDIs and adverse events from anticholinergics. Low persistence of treatment with anticholinergics for OAB [32] may also contribute to the burden and increase the safety risk for patients who abruptly stop OAB medications after drug regimens have been adjusted to account for DDIs. The potential for clinically relevant DDIs should be monitored for all patients, and DDIs should be carefully considered in high-risk populations such as patients $\geq 65$ years old [33].

Many hospital admissions of older adults for drug toxicity occur after administration of a drug known to cause DDIs [34]. Although continuous monitoring for DDIs and adjustment of medications require diligence on the part of treating clinicians to ensure patient safety, studies have shown that evaluating polypharmacy and DDIs and updating treatment plans accordingly is associated with decreased healthcare and medication costs $[35,36]$. Furthermore, deprescribing of medications should be considered for patients with OAB who are receiving polypharmacy; in such cases, it may be necessary for providers to carefully consider baseline medication use, prioritize medications, and discontinue or change medications (e.g., from anticholinergics for $\mathrm{OAB}$ to adrenergic agonists) to optimize clinical outcomes [27]. Use of a validated method to identify older patients at risk of adverse drug reactions, such as the GerontoNet ADR risk score, may facilitate this process [37]. 


\section{Drug Safety: Anticholinergic Burden Including Drugs for OAB}

\subsection{Guidelines for the Safe Prescribing of Medications}

A number of guidelines are available for clinicians to aid in clinical decision making, and many guidelines are geared toward use in older adults. The American Geriatrics Society Beers Criteria for Potentially Inappropriate Medication Use is arguably one of the most widely used guidelines in clinical practice and research. In 2019, the American Geriatrics Society published an update to the Beers Criteria [15], which aims to provide guidance to healthcare providers regarding the safe prescribing of medications in older adults. Additional guidelines include the screening tool of older people's prescriptions (STOPP) and the screening tool to alert to the right treatment (START), which were first published in 2008 and most recently updated in 2015 [38]. The goals of the STOPP and START criteria are to provide clinicians with information necessary to minimize inappropriate prescribing in older adults, including defining medications significantly associated with adverse drug reactions. Applying STOPP and START criteria has been shown to significantly improve the appropriateness of medication and reduce adverse drug reactions [38]. The Medication Appropriateness Index is another tool developed to serve as a sensitive measure in prescribing quality due to intervention by a pharmacist [39, 40]. As a whole, the numerous available guidelines aim to provide clinicians with the necessary information to effectively treat patients while minimizing unsafe and harmful prescribing practices.

\subsection{Guidelines for Anticholinergic Use}

Appropriate anticholinergic prescribing is particularly important in adults with OAB because anticholinergics are one of the primary pharmacologic treatments and are intended for long-term use. The 2019 Beers Criteria update includes $>50$ drugs with strong anticholinergic properties, many of which are recommended to avoid in older adults owing to an increased risk of confusion, dry mouth, constipation, and other common anticholinergic effects [15]. The Beers Criteria also recommends cautious use and monitoring of sodium levels for some anticholinergics, such as antipsychotics, selective-serotonin reuptake inhibitors, selective-norepinephrine reuptake inhibitor, and tricyclic antidepressants. High anticholinergic burden (ACB), which is the cumulative effect of taking one or more medications with anticholinergic activity, is associated with falls/fractures, cognitive decline, and increased mortality risk [11, $12,41]$. With alternatives to anticholinergics available for at-risk populations, prescribing of multiple anticholinergics should be avoided owing to DDIs and the increased risk of cognitive decline [42].

Despite this guidance, adults with $\mathrm{OAB}$ are commonly prescribed medications with high ACB. A database analysis of residents of US nursing homes showed that approximately $71 \%$ of residents with OAB or urinary incontinence were receiving anticholinergic agents; of those treated with anticholinergics for $\mathrm{OAB}, 77 \%$ were receiving additional medications with anticholinergic properties [29]. An analysis of patients (age range 65-97 years) receiving trospium for the treatment for $\mathrm{OAB}$, which is generally considered to have the lowest risk of DDIs of the anticholinergics for $\mathrm{OAB}$, showed that approximately $28 \%$ of patients had an ACB score of $\geq 2$ at baseline [43]. Use of anticholinergic medications is associated with an increased risk of incident dementia [12]; thus, treatment with anticholinergics in older adults and adults with dementia should be carefully considered. In a cross-sectional analysis of community-dwelling adults $\geq 65$ years old, approximately 5\% took an OABrelated anticholinergic medication, and adults with impaired cognition (e.g., mild cognitive impairment, dementia) were more likely to take anticholinergics than those without cognitive impairment [44]. Furthermore, $41 \%$ of adults who were taking anticholinergics were also taking cholinesterase inhibitors [44], which may not only cause both drugs to lose efficacy but is also likely to cause harm. Dual use of anticholinergics with cholinesterase inhibitors has been shown to lead to a faster rate of functional decline in activities of daily living [45].

\subsection{Considerations When Prescribing OAB Anticholinergics}

Clinicians should use caution when prescribing anticholinergics for the treatment of OAB, especially in frail older adult patients and when patients are taking other medications with anticholinergic properties [9]. Anticholinergics are also contraindicated in patients receiving solid oral potassium supplements because of reduced gastric motility caused by anticholinergics [9]. Further, owing to the high percentage of adults with OAB who also have comorbid cardiovascular and/or neuropsychiatric conditions [6, 7], clinicians should be especially cognizant of cardiovascular and CNS effects. Although adverse cardiovascular events are typically reported at low rates in clinical trials of anticholinergics for $\mathrm{OAB}$, post-marketing experience suggests that anticholinergics are associated with palpitations [46-50] and tachycardia (from anticholinergic effects on the heart) [46-48], as well as QT prolongation (from blockade of hERG channels) [46, 51]. QT prolongation may lead to the development of torsades de pointes (TdP), a potentially fatal ventricular arrhythmia. Drugs with a risk of TdP are 
categorized as (1) known risk of TdP; (2) possible risk of TdP; or (3) conditional risk of TdP [52]. With regard to effects on the CNS, oxybutynin, trospium, darifenacin, and solifenacin are associated with hallucinations, confusion, and somnolence $[46,48,49,51]$, and tolterodine is associated with disorientation and memory impairment [47]. Although CNS effects are not included within the US Food and Drug Administration-approved label for fesoterodine, consideration should be given to the potential for more general anticholinergic effects.

\section{Drug-Drug Interactions}

\subsection{General Considerations with Polypharmacy}

In populations with a high prevalence of comorbid medical conditions and polypharmacy, use of anticholinergics and drugs that are substrates of CYP2D6 is particularly concerning, as each additional medication leads to a greater risk of DDIs, adverse events, and potentially life-threatening situations. Further, a number of medications are known to cause QTc prolongation, which makes medication management difficult for patients who may be at higher risk for cardiac arrythmias. Assuming a 22\% likelihood of a drug being metabolized by CYP2D6, the probability of a patient taking at least one medication that is a substrate for CYP2D6 rapidly increases with the number of medications prescribed (Fig. 1), ultimately increasing the probability of a patient experiencing a clinically relevant DDI. In a recent retrospective analysis, residents of LTC facilities with OAB were taking a median of nine medications [53]. Using the above estimated likelihood, each resident receiving nine medications would therefore have an $89 \%$ probability of receiving at least one CYP2D6 substrate. Indeed, residents of LTCs with OAB have a greater overall use of medications that are substrates of CYP2D6 compared with residents without OAB (74\% vs $67 \%$, respectively), including significantly increased use of antidepressants (54\% vs $46 \%$ ); they also had significantly increased use of medications known to cause QTc prolongation (39\% vs $29 \%$ ) [53].

\subsection{Drugs with Clinically Significant CYP2D6 Metabolism}

As approximately one-quarter of currently used drugs are metabolized by CYP2D6, inhibition of CYP2D6, which leads to reduced enzyme activity and increased concentration of CYP2D6 substrates, is an important consideration for patients who are receiving polypharmacy. Thus, to identify clinically relevant CYP2D6 substrates in the treatment of $\mathrm{OAB}$, we searched the following four drug databases and references: (1) Drug Interactions: Flockhart Table ${ }^{\mathrm{TM}}$ [54];
(2) Drug Interaction Solutions: In Vivo CYP2D6 Substrates [55]; (3) Lexicomp Facts \& Comparisons Searchable Drug Information Database [56]; and (4) The Top 100 Drug Interactions: A Guide to Patient Management [57]. Review of four DDI databases or references indicates that 108 drugs approved for use in the USA are clinically relevant substrates of CYP2D6 (Table 2). These medications include common treatments for psychiatric disorders (e.g., depression, schizophrenia), cardiovascular disorders (e.g., hypertension, high cholesterol), and gastrointestinal disorders. A substantial number of these CYP2D6 substrates are also commonly used for the treatment of comorbidities often associated with OAB. Of the CYP2D6 substrates, 33 drugs are some of the most commonly prescribed drugs in the USA (i.e., included among the top 200 prescribed drugs) [58]. Approximately one-third (33/108) of these CYP2D6 substrates have ACB scores of 2 or 3 per the Anticholinergic Cognitive Burden Scale $[59,60]$, and 60 have risk of QT prolongation or TdP (Table 2).

When CYP2D6 substrates are co-administered with a CYP2D6 inhibitor, patients may experience supra-therapeutic levels of the CYP2D6 substrate owing to increased exposure from inhibited metabolism. This in turn leads to an increased risk of adverse events. These adverse effects commonly affect the CNS, leading to neurologic adverse events (e.g., seizures, serotonin toxicity, altered mental status), and are especially relevant for patients being treated for neurologic or psychiatric conditions with the CYP2D6 substrates listed in Table 2 [61, 62]. Similarly, treatment with analgesics (e.g., tramadol) can lead to adverse neurologic effects such as seizures or serotonin toxicity [63-65]. In addition

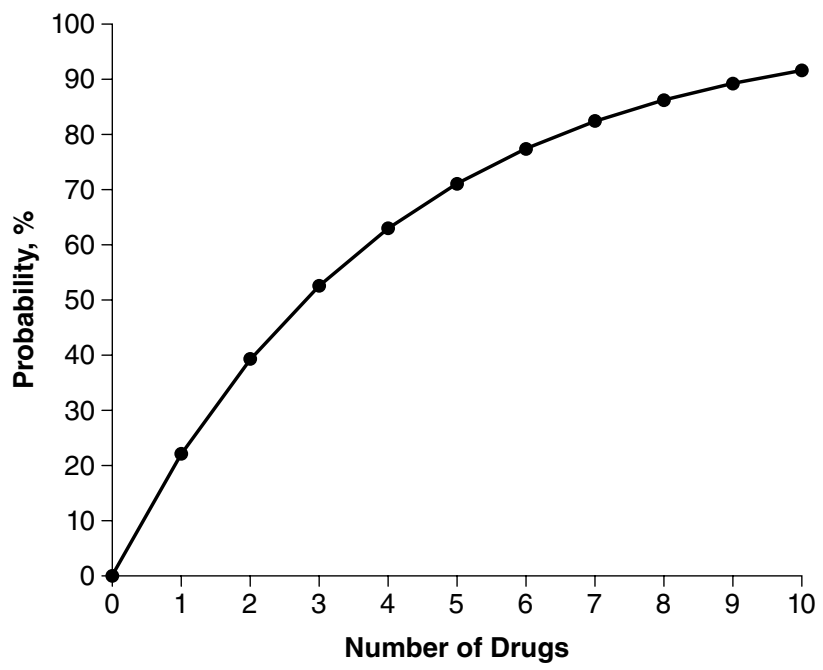

Fig. 1 Probability of a patient receiving a cytochrome P450 2D6 substrate. Probabilities are based on the assumption of a binomial distribution in which each drug prescribed is considered an independent event and the probability of each drug being a cytochrome P450 2D6 substrate is $22 \%$ 
Table 2 Therapeutic class, anticholinergic properties, and potential for QT prolongation of clinically relevant CYP2D6 substrates

\begin{tabular}{|c|c|c|c|}
\hline \multicolumn{4}{|l|}{ Therapeutic class } \\
\hline \multicolumn{4}{|c|}{ Overactive bladder and lower urinary tract disorders } \\
\hline Darifenacin & Fesoterodine & Tamsulosin ${ }^{\mathrm{a}}$ & Tolterodine $^{b}$ \\
\hline \multicolumn{4}{|l|}{ Psychiatric disorders } \\
\hline Amitriptyline $\mathrm{a}^{\mathrm{a}, \mathrm{b}}$ & Doxepin $^{b}$ & Mirtazapine $^{\mathrm{a}, \mathrm{b}}$ & Quetiapine $^{\mathrm{a}, \mathrm{b}}$ \\
\hline Amoxapine & Duloxetine $^{\mathrm{a}}$ & Nefazodone & Risperidone $^{\mathrm{a}, \mathrm{b}}$ \\
\hline Aripiprazole ${ }^{\mathrm{a}, \mathrm{b}}$ & Escitalopram $^{\mathrm{a}, \mathrm{b}}$ & Nortriptyline $^{b}$ & Sertraline $\mathrm{a}^{\mathrm{a} b \mathrm{~b}}$ \\
\hline Asenapine ${ }^{\mathrm{b}}$ & Fluoxetine $\mathrm{e}^{\mathrm{a}, \mathrm{b}}$ & Olanzapine $^{\mathrm{b}}$ & Thioridazine $^{\mathrm{b}}$ \\
\hline Brexpiprazole & Fluphenazine & Paliperidone $^{\mathrm{b}}$ & Trazodone $e^{a, b}$ \\
\hline Cariprazine & Fluvoxamine $^{\mathrm{b}}$ & Paroxetine $^{\mathrm{a}, \mathrm{b}}$ & Trimipramine $^{\mathrm{b}}$ \\
\hline Chlorpromazine $^{\mathrm{b}}$ & Haloperidol $^{\mathrm{b}}$ & Perphenazine $^{\mathrm{b}}$ & Venlafaxine $^{\mathrm{a}, \mathrm{b}}$ \\
\hline Citalopram ${ }^{\mathrm{a}, \mathrm{b}}$ & Iloperidone $^{\mathrm{b}}$ & Pimavanserin ${ }^{\mathrm{b}}$ & Vilazodone \\
\hline Clomipramine $^{\mathrm{b}}$ & Imipramine $^{\mathrm{b}}$ & Pimozide $^{\mathrm{b}}$ & Vortioxetine \\
\hline Clozapine $^{\mathrm{b}}$ & Loxapine & Prochlorperazine & \\
\hline Desipramine $^{\mathrm{b}}$ & Maprotiline $^{\mathrm{b}}$ & Protriptyline & \\
\hline \multicolumn{4}{|c|}{ Cardiovascular disorders } \\
\hline Carvedilol $^{\mathrm{a}}$ & Metoprolol $^{\mathrm{a}}$ & Propafenone $^{\mathrm{b}}$ & Timolol $^{\mathrm{a}}$ \\
\hline Clonidine $^{\mathrm{a}}$ & Mexiletine & Propranolol $^{\mathrm{a}}$ & \\
\hline Flecainide $^{\mathrm{b}}$ & Nebivolol $^{\mathrm{a}}$ & Ranolazine $^{\mathrm{b}}$ & \\
\hline Lovastatin $^{\mathrm{a}}$ & Procainamide $^{\mathrm{b}}$ & Simvastatin $^{\mathrm{a}}$ & \\
\hline \multicolumn{4}{|l|}{ Neurologic disorders } \\
\hline Deutetrabenazine $^{b}$ & Fingolimod $^{\mathrm{b}}$ & Tetrabenazine $^{\mathrm{b}}$ & Valbenazine $^{\mathrm{b}}$ \\
\hline Donepezil ${ }^{\mathrm{a}, \mathrm{b}}$ & Galantamine $^{\mathrm{b}}$ & & \\
\hline \multicolumn{4}{|c|}{ Supportive care, pain, and gastrointestinal disorders } \\
\hline Almotriptan & Dihydrocodeine & Metaxalone & Oxycodone $^{\mathrm{a}}$ \\
\hline Chlorpheniramine & Diphenhydramine $^{\mathrm{b}}$ & Methadone $^{\mathrm{b}}$ & Palonosetron $^{\mathrm{b}}$ \\
\hline Codeine & Dolasetron $^{\mathrm{b}}$ & Metoclopramide $^{\mathrm{b}}$ & Promethazine $^{\mathrm{a}, \mathrm{b}}$ \\
\hline Desloratadine & Hydrocodone $\mathrm{e}^{\mathrm{a}, \mathrm{b}}$ & Netupitant & Tramadol $^{\mathrm{a}, \mathrm{b}}$ \\
\hline Dextromethorphan & Loratadine $^{\mathrm{a}}$ & Ondansetron $^{\mathrm{a}, \mathrm{b}}$ & \\
\hline \multicolumn{4}{|l|}{ Antineoplastic } \\
\hline Gefitinib & Ibrutinib & Rucaparib $^{\text {b }}$ & Tamoxifen $^{\mathrm{b}}$ \\
\hline \multicolumn{4}{|l|}{ Other } \\
\hline Amphetamine $^{\mathrm{a}}$ & Dacomitinib & Lofexidine $^{b}$ & Pitolisant $^{\mathrm{b}}$ \\
\hline Atomoxetine $^{\mathrm{a}, \mathrm{b}}$ & Dextroamphetamine $^{a}$ & Luliconazole & Ponatinib \\
\hline Cevimeline & Eliglustat $^{\mathrm{b}}$ & Methamphetamine & Primaquine $^{\mathrm{b}}$ \\
\hline Chloroquine $^{\mathrm{b}}$ & Fenfluramine & Methylphenidate $^{\mathrm{a}}$ & Ritonavir \\
\hline Cinacalcet & Flibanserin & Panobinostat $^{\mathrm{b}}$ & Umeclidinium \\
\hline
\end{tabular}

Drug names in bold have scores of 2 or 3 according to the Anticholinergic Cognitive Burden Scale [59], where 2 = evidence from the literature, prescribing information, or expert opinion of clinical effect and $3=$ evidence from the literature, prescribing information, or expert opinion that the medication may cause delirium. Drugs were cross-referenced against reports by Salahudeen et al. [60]

CYP cytochrome P450

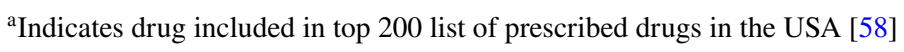

${ }^{\mathrm{b}}$ Indicates drug with a risk of QT prolongation and/or causing torsades de pointes [52]

to neurologic adverse effects, patients may experience clinically significant cardiovascular adverse effects such as bradycardia and hypotension when CYP2D6 inhibitors are administered with $\beta$-blockers that are CYP2D6 substrates (e.g., metoprolol, carvedilol) [66], which is particularly relevant for patients receiving treatment for heart failure.
When it is necessary to prescribe a drug that is a CYP2D6 inhibitor, treating clinicians should be aware of drugs that are CYP2D6 substrates and monitor for adverse events or modify doses accordingly.

Five CYP2D6 substrates have a boxed warning or documented contraindication when co-administered with 
CYP2D6 inhibitors (Table 3). These drugs should generally not be co-administered with CYP2D6 inhibitors, and alternatives should be considered. Because drugs that are CYP2D6 inhibitors may not contain corresponding boxed warnings for all medications metabolized by CYP2D6, DDIs between newly prescribed CYP2D6 inhibitors and substrates can often be overlooked. The total effect of the concurrent administration of multiple drugs that inhibit CYP2D6 is unknown, and some increase in inhibition is likely. Thus, treating clinicians should carefully review patient treatment plans and revise medication regimens to avoid the administration of multiple CYP2D6 inhibitors. Further, in patients receiving polypharmacy, it is especially important to perform medication reviews at every patient visit to ensure optimal treatment regimens and to determine whether it is appropriate to substitute or stop prescribing certain medications. Clinicians should also encourage medication adherence when counseling patients because nonadherence may be additionally problematic if dose adjustments have been made to account for DDIs.

\subsection{OAB Medications and CYP2D6 Substrates and Inhibitors}

The 2019 update to the American Urological Association/Society of Urodynamics, Female Pelvic Medicine and Urogenital Reconstruction guidelines for the management of OAB now recommends the use of combination therapy with anticholinergics and $\beta_{3}$-adrenergic agonists for patients refractory to monotherapy [9]. Of the drugs approved for the treatment of OAB or lower urinary tract symptoms, three of the anticholinergics (darifenacin, fesoterodine, tolterodine) and one $\alpha_{1}$-adrenergic receptor blocker (tamsulosin) are CYP2D6 substrates. Furthermore, darifenacin is also a CYP2D6 inhibitor [57], and in vitro and in vivo results indicate that mirabegron, a $\beta_{3}$-adrenergic receptor agonist, is a moderate inhibitor of CYP2D6 [67, 68]. In healthy women, co-administration of mirabegron with tolterodine increased tolterodine peak plasma concentration and area under the curve from 0 to 24 hours approximately two-fold and resulted in a significant QTc prolongation, as measured by an electrocardiogram [69]. Tolterodine and fesoterodine are converted to an active metabolite, 5-hydroxymethyl tolterodine, that is further metabolized by CYP2D6 and CYP3A4 [70]. Altering the metabolism of CYP2D6 and CYP3A4, whether through patient factors (e.g., poor vs extensive metabolizers) or through therapeutics, in individuals receiving fesoterodine results in an increase (2.3- to 2.5fold) in the area under the curve of the active metabolite [71]. Thus, combination therapy with mirabegron and a CYP2D6 substrate for OAB (e.g., tolterodine, fesoterodine) should be accompanied by careful patient monitoring, particularly in patients taking other drugs that could have DDIs. In the case of CYP2D6 inhibition with mirabegron, patients receiving anticholinergic drugs that are CYP2D6 substrates for common comorbid conditions may experience increased ACB and associated risks, and such use should be avoided [72].

\subsection{Co-Administration of OAB CYP2D6 Inhibitors and Non-OAB Medications}

For adults with $\mathrm{OAB}$ who are prescribed or may be receiving a new prescription for mirabegron, careful consideration of co-administered medications should be undertaken. Co-administration of mirabegron with metoprolol, a $\beta$-blocker approved for the treatment of hypertension that is a CYP2D6 substrate, has been shown to increase metoprolol peak plasma concentration 1.9-fold and total exposure 3.3-fold [68], which represents a dose three times greater than the intended dosage. Similarly, coadministration of mirabegron with desipramine, a tricyclic antidepressant that is also a CYP2D6 substrate, has been shown to increase desipramine peak plasma concentration 1.8 -fold and total exposure 3.4-fold [68]. The effect of mirabegron on the plasma concentration of metoprolol and

Table 3 CYP2D6 substrates with a boxed warning or other contraindication when co-administered with a CYP2D6 inhibitor

\begin{tabular}{lll}
\hline Drug & Indication & Risk when co-administered with CYP2D6 inhibitor \\
\hline Codeine & Pain management & Respiratory depression, extreme sleepiness, confusion, shallow breathing [75] \\
Eliglustat tartrate & Gaucher disease & Prolongation of PR, QTc, and/or QRS interval [76] \\
Methadone & $\begin{array}{c}\text { Opioid use disorder, pain man- } \\
\text { agement }\end{array}$ & $\begin{array}{l}\text { Respiratory depression [77] } \\
\text { Schizophrenia }\end{array}$ \\
$\begin{array}{l}\text { Thioridazine } \\
\text { Tramadol }^{\text {a }}\end{array}$ & Pain management & $\begin{array}{c}\text { QTc prolongation, torsades de pointes [78] } \\
\text { Seizures, serotonin toxicity (mental status change, autonomic instability, } \\
\text { neuromuscular aberrations, gastrointestinal symptoms) [63] }\end{array}$ \\
\hline
\end{tabular}

CYP cytochrome $\mathrm{P} 450$

${ }^{\mathrm{a}}$ Indicates drug included in the top 200 list of prescribed drugs in the USA [58] 
desipramine is greater than that reported with tolterodine and fesoterodine because CYP2D6 is the primary pathway for metoprolol and desipramine metabolism. Additionally, the magnitude of DDIs observed between mirabegron and CYP2D6 substrates may be explained by the mechanismbased inhibition property of mirabegron or by genetic polymorphisms in CYP2D6 [73]. Although data reporting the effect of mirabegron on CYP2D6 substrates are limited, it is reasonable, based on the data summarized above, to assume an approximately two- to three-fold increase in plasma concentrations of typical CYP2D6 substrates. Careful monitoring of patients receiving CYP2D6 substrates during the initiation and discontinuation of mirabegron is warranted [72]. Alternatively, a $\beta_{3}$-adrenergic agonist that does not inhibit CYP2D6 enzymes, such as vibegron [74], could be considered for patients taking CYP2D6 substrates.

\section{Conclusions}

Patients with $\mathrm{OAB}$ experience a greater number of comorbid medical conditions and have a higher prevalence of polypharmacy compared with patients without OAB. Many drugs used to treat comorbid conditions have clinically relevant anticholinergic properties and/or are CYP2D6 substrates, which may make management of $\mathrm{OAB}$ difficult owing to the potential for anticholinergic side effects and an increased risk of potentially harmful DDIs. Current pharmacologic treatments for $\mathrm{OAB}$ include anticholinergics and $\beta_{3}$-adrenergic agonists; however, four drugs approved for the treatment of OAB or lower urinary tract symptoms are CYP2D6 substrates, and two are CYP2D6 inhibitors. Treating clinicians should carefully consider medications prescribed and refine regimens as necessary to minimize potential harms related to DDIs while maximizing benefit in the treatment of OAB.

Acknowledgements The authors thank Adam Carrera, PharmD, and Noelia Goti of Urovant Sciences for assistance with reviewing and cross-referencing CYP2D6 substrates. Medical writing and editorial support was provided by Krystina Neuman, PhD, CMPP, of The Curry Rockefeller Group, LLC (Tarrytown, NY, USA), and was funded by Urovant Sciences (Irvine, CA, USA).

\section{Declarations}

Funding Funding for the preparation of this article was provided by Urovant Sciences.

Conflict of Interest Matthew P. Rutman is a consultant for Boston Scientific and Urovant Sciences. John R. Horn is a co-author and publisher of The Top 100 Drug Interactions: A Guide to Patient Management and a consultant to Urovant Sciences and Seegnal US. Diane K. Newman is an advisor for Urovant Sciences. Richard G. Stefanacci is an advisor for Urovant Sciences.
Ethics Approval Not applicable.

Consent to Participate Not applicable.

Consent for Publication Not applicable.

Availability of Data and Material All resources analyzed in the writing of this review are listed in this published article.

Code Availability Not applicable.

Open Access This article is licensed under a Creative Commons Attribution-NonCommercial 4.0 International License, which permits any non-commercial use, sharing, adaptation, distribution and reproduction in any medium or format, as long as you give appropriate credit to the original author(s) and the source, provide a link to the Creative Commons licence, and indicate if changes were made. The images or other third party material in this article are included in the article's Creative Commons licence, unless indicated otherwise in a credit line to the material. If material is not included in the article's Creative Commons licence and your intended use is not permitted by statutory regulation or exceeds the permitted use, you will need to obtain permission directly from the copyright holder. To view a copy of this licence, visit http://creativecommons.org/licenses/by-nc/4.0/.

\section{References}

1. Coyne KS, Sexton CC, Vats V, et al. National community prevalence of overactive bladder in the United States stratified by sex and age. Urology. 2011;77(5):1081-7.

2. Stewart WF, Van Rooyen JB, Cundiff GW, et al. Prevalence and burden of overactive bladder in the United States. World J Urol. 2003;20(6):327-36.

3. Gorina Y, Schappert S, Bercovitz A, et al. Prevalence of incontinence among older Americans. Vital Health Stat 3. 2014;(36):1-33.

4. Zarowitz BJ, Allen C, O'Shea T, et al. Clinical burden and nonpharmacologic management of nursing facility residents with overactive bladder and/or urinary incontinence. Consult Pharm. 2015;30(9):533-42.

5. Newman DK. Urinary incontinence in long-term care facilities: current clinical practice. Director. 2004;12(1):30-3.

6. Andersson KE, Sarawate C, Kahler KH, et al. Cardiovascular morbidity, heart rates and use of antimuscarinics in patients with overactive bladder. BJU Int. 2010;106(2):268-74.

7. Asche CV, Kim J, Kulkarni AS, et al. Presence of central nervous system, cardiovascular and overall co-morbidity burden in patients with overactive bladder disorder in a real-world setting. BJU Int. 2012;109(4):572-80.

8. Ganz ML, Liu J, Zou KH, et al. Real-world characteristics of elderly patients with overactive bladder in the United States. Curr Med Res Opin. 2016;32(12):1997-2005.

9. Lightner DJ, Gomelsky A, Souter L, Vasavada SP. Diagnosis and Treatment of Overactive Bladder (Non-Neurogenic) in Adults: AUA/SUFU Guideline Amendment 2019. J Urol. 2019;202(3):558-63.

10. Rai BP, Cody JD, Alhasso A, et al. Anticholinergic drugs versus non-drug active therapies for non-neurogenic overactive bladder syndrome in adults. Cochrane Database Syst Rev. 2012;12(12):CD003193.

11. Szabo SM, Gooch K, Schermer C, et al. Association between cumulative anticholinergic burden and falls and fractures in 
patients with overactive bladder: US-based retrospective cohort study. BMJ Open. 2019;9(5):e026391.

12. Dmochowski RR, Thai $\mathrm{S}$, Iglay $\mathrm{K}$, et al. Increased risk of incident dementia following use of anticholinergic agents: a systematic literature review and meta-analysis. Neurourol Urodyn. 2021;40(1):28-37.

13. Welk B, McArthur E. Increased risk of dementia among patients with overactive bladder treated with an anticholinergic medication compared to a beta-3 agonist: a population-based cohort study. BJU Int. 2020;126(1):183-90.

14. Gray SL, Anderson ML, Dublin S, et al. Cumulative use of strong anticholinergics and incident dementia: a prospective cohort study. JAMA Intern Med. 2015;175(3):401-7.

15. American Geriatrics Society Beers Criteria Update Expert Panel. American Geriatrics Society 2019 Updated AGS Beers Criteria ${ }^{\circledR}$ for potentially inappropriate medication use in older adults. J Am Geriatr Soc. 2019;67(4):674-94.

16. Dahlinger D, Aslan S, Pietsch M, et al. Assessment of inhibitory effects on major human cytochrome P450 enzymes by spasmolytics used in the treatment of overactive bladder syndrome. Ther Adv Urol. 2017;9(7):163-77.

17. Koppel R, Metlay JP, Cohen A, et al. Role of computerized physician order entry systems in facilitating medication errors. JAMA. 2005;293(10):1197-203.

18. Jamoom EW, Yang N, Hing E. Adoption of certified electronic health record systems and electronic information sharing in physician offices: United States, 2013 and 2014. NCHS Data Brief. 2016;(236):1-8.

19. Classen DC, Holmgren AJ, Co Z, et al. National trends in the safety performance of electronic health record systems from 2009 to 2018. JAMA Netw Open. 2020;3(5):e205547.

20. Darkow T, Fontes CL, Williamson TE. Costs associated with the management of overactive bladder and related comorbidities. Pharmacotherapy. 2005;25(4):511-9.

21. Durden E, Walker D, Gray S, et al. The economic burden of overactive bladder $(\mathrm{OAB})$ and its effects on the costs associated with other chronic, age-related comorbidities in the United States. Neurourol Urodyn. 2018;37(5):1641-9.

22. Arana A, Margulis AV, McQuay LJ, et al. Variation in cardiovascular risk related to individual antimuscarinic drugs used to treat overactive bladder: a UK cohort study. Pharmacotherapy. 2018;38(6):628-37.

23. Fox C, Smith T, Maidment I, et al. Effect of medications with anti-cholinergic properties on cognitive function, delirium, physical function and mortality: a systematic review. Age Ageing. 2014;43(5):604-15.

24. Wagg A, Arumi D, Herschorn S, et al. A pooled analysis of the efficacy of fesoterodine for the treatment of overactive bladder, and the relationship between safety, co-morbidity and polypharmacy in patients aged 65 years or older. Age Ageing. 2017;46(4):620-6.

25. Harris-Kojetin L, Sengupta M, Lendon JP, et al. Long-term care providers and services users in the United States, 2015-2016. Vital Health Stat. 2019;3(43):1-78.

26. Kanwar A, Singh M, Lennon R, et al. Frailty and health-related quality of life among residents of long-term care facilities. J Aging Health. 2013;25(5):792-802.

27. Halli-Tierney AD, Scarbrough C, Carroll D. Polypharmacy: evaluating risks and deprescribing. Am Fam Physician. 2019;100(1):32-8.

28. Jokanovic N, Tan ECK, Dooley MJ, et al. Prevalence and factors associated with polypharmacy in long-term care facilities: a systematic review. J Am Med Dir Assoc. 2015;16(6):535.e1-12.

29. Zarowitz BJ, Allen C, O'Shea T, et al. Challenges in the pharmacological management of nursing home residents with overactive bladder or urinary incontinence. J Am Geriatr Soc. 2015;63(11):2298-307.

30. Yehoshua A, Chancellor M, Vasavada S, et al. Health resource utilization and cost for patients with incontinent overactive bladder treated with anticholinergics. J Manag Care Spec Pharm. 2016;22(4):406-13.

31. Moura CS, Acurcio FA, Belo NO. Drug-drug interactions associated with length of stay and cost of hospitalization. J Pharm Pharm Sci. 2009;12(3):266-72.

32. Yeowell G, Smith P, Nazir J, et al. Real-world persistence and adherence to oral antimuscarinics and mirabegron in patients with overactive bladder $(\mathrm{OAB})$ : a systematic literature review. BMJ Open. 2018;8(11):e021889.

33. Hines LE, Murphy JE. Potentially harmful drug-drug interactions in the elderly: a review. Am J Geriatr Pharmacother. 2011;9(6):364-77.

34. Juurlink DN, Mamdani M, Kopp A, et al. Drug-drug interactions among elderly patients hospitalized for drug toxicity. JAMA. 2003;289(13):1652-8.

35. Arnold RJG, Tang J, Schrecker J, et al. Impact of definitive drugdrug interaction testing on medication management and patient care. Drugs Real World Outcomes. 2018;5(4):217-24.

36. Kojima G, Bell C, Tamura B, et al. Reducing cost by reducing polypharmacy: the polypharmacy outcomes project. J Am Med Dir Assoc. 2012;13(9):818.e11-5.

37. Onder G, Petrovic M, Tangiisuran B, et al. Development and validation of a score to assess risk of adverse drug reactions among in-hospital patients 65 years or older: the GerontoNet ADR risk score. Arch Intern Med. 2010;170(13):1142-8.

38. O'Mahony D, O'Sullivan D, Byrne S, et al. STOPP/START criteria for potentially inappropriate prescribing in older people: version 2. Age Ageing. 2015;44(2):213-8.

39. Hanlon JT, Schmader KE. The medication appropriateness index at 20: where it started, where it has been, and where it may be going. Drugs Aging. 2013;30(11):893-900.

40. Hanlon JT, Schmader KE, Samsa GP, et al. A method for assessing drug therapy appropriateness. J Clin Epidemiol. 1992;45(10):1045-51.

41. Ruxton K, Woodman RJ, Mangoni AA. Drugs with anticholinergic effects and cognitive impairment, falls and all-cause mortality in older adults: a systematic review and meta-analysis. Br J Clin Pharmacol. 2015;80(2):209-20.

42. Fixen DR. 2019 AGS Beers criteria for older adults. Pharmacy Today. 2019;25(11):42-54.

43. Ivchenko A, Bödeker RH, Neumeister C, et al. Anticholinergic burden and comorbidities in patients attending treatment with trospium chloride for overactive bladder in a real-life setting: results of a prospective non-interventional study. BMC Urol. 2018;18(1):80.

44. Green AR, Segal J, Tian J, et al. Use of bladder antimuscarinics in older adults with impaired cognition. J Am Geriatr Soc. 2017;65(2):390-4.

45. Sink KM, Thomas J 3rd, Xu H, et al. Dual use of bladder anticholinergics and cholinesterase inhibitors: long-term functional and cognitive outcomes. J Am Geriatr Soc. 2008;56(5):847-53

46. Ditropan XL (oxybutynin chloride extended-release tablets). Full prescribing information. Titusville (NJ): Janssen Pharmaceuticals; 2016.

47. Detrol ${ }^{\circledR}$ (tolterodine tartrate). Full prescribing information. New York (NY): Pfizer; 2012.

48. Sanctura ${ }^{\circledR}$ (trospium chloride). Full prescribing information. Irvine (CA): Allergan, Inc.; 2012.

49. Enablex ${ }^{\circledR}$ (darifenacin). Full prescribing information. Stein: Novartis Pharma Stein AG; 2008.

50. Toviaz ${ }^{\circledR}$ (fesoterodine fumarate). Full prescribing information. New York (NY): Pfizer Inc.; 2011. 
51. VESIcare ${ }^{\circledR}$ (solifenacin succinate). Full prescribing information. Deerfield (IL): Astellas Pharma US, Inc.; 2020.

52. Woosley RL, Heise CW, Gallo T, et al. QTdrugs list. 2020. https:// www.crediblemeds.org/. Accessed 17 Apr 2020.

53. Yeaw J, Shah D, Kincaid A, et al. Overactive bladder in the United States long-term care setting is associated with significant burden and increased healthcare resource utilization and costs: a retrospective database study. ISPOR; 19-20 May 2020; virtual.

54. Flockhart DA. Drug interactions: Flockhart Table ${ }^{\mathrm{TM}}$. 2019. https:// drug-interactions.medicine.iu.edu/Main-Table.aspx. Accessed 12 Aug 2020.

55. Drug Interaction Solutions: In Vivo CYP2D6 Substrates. 2020. https://www.druginteractionsolutions.org/solutions/human-invitro-datasets/. Accessed 12 Aug 2020.

56. Lexicomp. Facts \& comparisons searchable drug information databases. 2020. https://www.wolterskluwercdi.com/facts-compa risons-online/databases/. Accessed 12 Aug 2020.

57. Hansten PD, Horn JR. The Top 100 Drug Interactions: A Guide to Patient Management. Freeland (WA): H\&H Publications, LLC; 2019.

58. Fuentes AV, Pineda MD, Venkata KCN. Comprehension of top 200 prescribed drugs in the US as a resource for pharmacy teaching, training and practice. Pharmacy (Basel). 2018;6(2):43.

59. Hanlon P, Quinn TJ, Gallacher KI, et al. Assessing risks of polypharmacy involving medications with anticholinergic properties. Ann Fam Med. 2020;18(2):148-55.

60. Salahudeen MS, Duffull SB, Nishtala PS. Anticholinergic burden quantified by anticholinergic risk scales and adverse outcomes in older people: a systematic review. BMC Geriatr. 2015;15:31.

61. Hiemke C, Bergemann N, Clement HW, et al. Consensus guidelines for therapeutic drug monitoring in neuropsychopharmacology: update 2017. Pharmacopsychiatry. 2018;51(1-02):9-62.

62. Bleakley S. Antidepressant drug interactions: evidence and clinical significance. Prog Neurol Psychiatry. 2016;20(3):21-7.

63. Ultram ${ }^{\circledR}$ (tramadol hydrochloride). Full prescribing information. Janssen Pharmaceuticals; 2019.

64. Hassamal S, Miotto K, Dale W, et al. Tramadol: understanding the risk of serotonin syndrome and seizures. Am J Med. 2018;131(11):1382.e1-6.

65. Park SH, Wackernah RC, Stimmel GL. Serotonin syndrome: is it a reason to avoid the use of tramadol with antidepressants? J Pharm Pract. 2014;27(1):71-8.
66. Bebawi E, Jouni SS, Tessier AA, et al. A metoprolol-terbinafine combination induced bradycardia. Eur J Drug Metab Pharmacokinet. 2015;40(3):295-9.

67. Takusagawa S, Miyashita A, Iwatsubo T, et al. In vitro inhibition and induction of human cytochrome P450 enzymes by mirabegron, a potent and selective beta3-adrenoceptor agonist. Xenobiotica. 2012;42(12):1187-96.

68. Krauwinkel W, Dickinson J, Schaddelee M, et al. The effect of mirabegron, a potent and selective beta3-adrenoceptor agonist, on the pharmacokinetics of CYP2D6 substrates desipramine and metoprolol. Eur J Drug Metab Pharmacokinet. 2014;39(1):43-52.

69. Nomura Y, Iitsuka H, Toyoshima J, et al. Pharmacokinetic drug interaction study between overactive bladder drugs mirabegron and tolterodine in Japanese healthy postmenopausal females. Drug Metab Pharmacokinet. 2016;31(6):411-6.

70. Malhotra B, Darsey E, Crownover P, et al. Comparison of pharmacokinetic variability of fesoterodine vs. tolterodine extended release in cytochrome P450 2D6 extensive and poor metabolizers. Br J Clin Pharmacol. 2011;72(2):226-34.

71. Malhotra B, Sachse R, Wood N. Evaluation of drug-drug interactions with fesoterodine. Eur J Clin Pharmacol. 2009;65(6):551-60.

72. Myrbetriq ${ }^{\circledR}$ (mirabegron extended-release tablets). Full prescribing information. Northbrook (IL): Astellas Pharma US, Inc.; 2018.

73. Deodhar M, Al Rihani SB, Arwood MJ, et al. Mechanisms of CYP450 inhibition: understanding drug-drug interactions due to mechanism-based inhibition in clinical practice. Pharmaceutics. 2020;12(9):846.

74. Gemtesa ${ }^{\circledR}$ (vibegron). Full prescribing information. Irvine (CA): Urovant Sciences, Inc.; 2020.

75. Codeine sulfate. Full prescribing information. Eatontown (NJ): West-Ward Pharmaceuticals Corp.; 2017.

76. Cerdelga ${ }^{\mathrm{TM}}$ (eliglustat). Full prescribing information. Waterford: Genzyme Corporation; 2014.

77. Dolophine (methadone). Full prescribing information. Eatontown (NJ): West-Ward Pharmaceuticals Corp.; 2018.

78. Thioridazine $\mathrm{HCl}$. Full prescribing information. Rockford (IL): Mylan Pharmaceuticals Inc.; 2019. 